\title{
KINERJA GURU DALAM IMPLEMENTASI KURIKULUM 2013 DI SMA ISLAM AL-MA'ARIF PANDAN INDAH KABUPATEN LOMBOK TENGAH PROVINSI NUSA TENGGARA BARAT
}

\author{
Bahman $^{1}$ dan Dian Hidayati ${ }^{2}$ \\ 1, 2 Manajemen Pendidikan,Universitas Ahmad Dahlan, Yogyakarta - Indonesia \\ J1. Pramuka No. 42, Pandeyan, Kecamatan Umbulharjo, Kota Yogyakarta, 55161 \\ ${ }^{1}$ Email: wijayabahman@gmail.com \\ ${ }^{2}$ Email: dian.hidayati@mp.uad.ac.id
}

\begin{abstract}
ABSTRAK
Kinerja guru menjadi suatu keharusan dalam peningkatkan kualitas layanan pembelajaran yang mencakup pelaksanaan kurikulum untuk semua komponen mata pembelajaran. Kurikulum merupakan kumpulan; isi, tujuan, dan cara yang digunakan oleh guru untuk mencapai tujuan pendidikan di sekolah. Penelitian ini bertujuan untuk mengetahui kinerja guru dan hambatan yang dihadapi guru SMA Islam Al-Ma'arif Pandan Indah Kabupaten Lombok Tengah Provinsi Nusa Tenggara Barat dalam implementasi Kurikulum 2013. Untuk mencapai tujuan tersebut, penelitian ini mengunakan pendekatan kualitatif deskriptif. Sedangkan subjek penelitian adalah pengawas sekolah, kepala sekolah, wakil kepala sekolah bidang kurikulum, guru pendamping K-13 dan guru mata pelajaran. Teknik pengumpulan data dilakukan melalui wawancara, observasi, dan studi dokumentasi. Prosedur analisis data adalah reduksi data, display data, dan verifikasi data.
\end{abstract}

Kata kunci: Kinerja Guru, implementasi Kurikulum 2013

\begin{abstract}
Teacher performance is a necessity in improving the quality of learning services which includes the implementation of the curriculum for all components of the learning eye. The curriculum is a collection; the contents, objectives, and methods used by the teacher to achieve educational goals in school. This study aims to determine the teacher's performance and the obstacles faced by ISLAM AL-MA'ARIF high school teachers Pandan Indah district Lombok Tengah province Nusa Tenggara Barat in the implementation of the 2013 curriculum. To achieve this goal, this study uses a descriptive qualitative approach. While the subjects of the study were school supervisors, principals, deputy principals in the curriculum, $K-13$ assistant teachers and subject teachers. Data collection techniques are carried out through interviews, observation, and documentation studies. The data analysis procedure is data reduction, data display, and data verification.
\end{abstract}

Keywords: Teacher Performance, 2013 Curriculum implementation

\section{PENDAHULUAN}

Penyelenggaraan pendidikan di Indonesia merupakan suatu sistem pendidikan nasion al yang diatur secara sistematis. Pendidikan nasional berfungsi mengembangkan kemampu an dan membentuk watak serta peradaban bangsa yang bermartabat dalam rangka mencerd askan kehidupan bangsa, bertujuan untuk berkembangnya potensi peserta didik agar menjadi manusia yang beriman dan bertakwa kepada Tuhan Yang Maha Esa, berakhlak mulia, sehat, berilmu, cakap, kreatif, mandiri, dan menjadi warga negara yang demokratis serta bertanggung jawab (UU No. 20 Tahun 2003). Peningkatan mutu pendidikan 
ditentukan oleh kesiapan sumber daya yang ada termasuk sekolah dan guru sebagai manusia yang terlibat dalam proses pendidikan. Sekolah sebagai lembaga pendidikan formal yang harus mampu mengembangkan seluruh potensi yang dimiliki oleh peserta didik.

Guru sebagai pekerja harus berkemampuan yang meliputi penguasaan materi pelajaran, penguasaan profesional keguruan dan pendidikan, penguasaan cara-cara menyesuaikan diri dan berkepribadian untuk melaksanakan tugasnya, disamping itu guru harus merupakan pribadi yang berkembang dan bersifat dinamis. Penerapan Kurikulum 2013 menuntut kerjasama yang optimal dari segenap komponen di sekolah, seperti yang diutarakan Mulyasa (2014) bahwa keberhasilan pengembangan kurikulum dan pembelajara n didukung oleh kinerja team yang kompak dan transparan dari berbagai pihak yang terlibat dalam pendidikan. Oleh karena itu yang menjadi pokok persoalan adalah bagaimana tanggapan dari para guru itu sendiri sebagai pelaksana dan pengembang kurikulum tersebut? Dan yang paling penting adalah bagaimana meningkatkan peran dan pemahaman guru dan penyelenggara pendidikan lainnya terhadap implementasi Kurikulum 2013 ?, sehingga mereka bisa menjadikan Kurikulum 2013 sebagai acuan dalam proses pembelajaran di sekolah.

Istilah kinerja menurut Poerwadarminta (2010) berarti "sesuatu yang dicapai," atau "prestasi yang diperlihatkan," atau "kemampuan kerja,". Jadi secara sederhana dapat dikemukakan bahwa kinerja sebagai prestasi kerja, pelaksanaan kerja, pencapaian kerja, hasil kerja atau unjuk kerja. Mulyasa (2014) mejelaskan bahwa kinerja adalah unjuk kerja seseorang yang ditunjukkan dalam penampilan, perbuatan, dan prestasi kerjanya sebagai akumulasi dari pengetahuan, keterampilan, nilai dan sikap yang telah dimilikinya.

Indikator-indikator Kinerja Guru Indikator kinerja menganjurkan sudut pandang prospektif (harapan ke depan) dari pada retrospektif (melihat ke belakang). Hal ini menunjukkan jalan pada aspek kinerja yang perlu diobservasi. Wibowo (2014) menyatakan bahwa ada tujuh indikator kinerja, dua di antaranya mempunyai peran sangat penting, yaitu tujuan dan motif. Kinerja ditentukan oleh tujuan yang hendak dicapai dan untuk melakukannya diperlukan adanya motif. Tanpa adanya dorongan motif untuk mencapai tujuan, kinerja tidak akan berjalan. Dengan demikian, tujuan dan motif menjadi indikator utama dari kinerja.

Hasil penilaian kinerja guru dapat bermanfaat untuk menyusun profil kinerja guru sebagai input dalam penyusunan program Pengembangan Profesi Berkelanjutan (PKB). Hasil penilaian kinerja guru juga merupakan dasar penetapan perolehan angka kredit guru 
dalam rangka pengembangan karir guru sebagaimana diamanahkan dalam Peraturan Menteri Negara Pendayagunaan Aparatur Negara dan Reformasi Birokrasi Nomor 16 Tahun 2009 tentang jabatan fungsional guru dan angka kreditnya.

Menurut Bobbit di dalam Kurinasih dan Sani (2014) Curriculum as an idea, has its roots in the Latin word for race-course, explaining the curriculum as the course of deeds and experiences thought which children become the adult they should be, for success in adult society.

Kurikulum sebagai suatu gagasan, telah memiliki akar kata bahasa Latin racesource, menjelaskan kurikulum sebagai mata pelajaran perbuatan dan pengalaman yang dialami anak-anak sampai dewasa, agar kelak sukses di dalam masyarakat). Demikian juga menurut Hilda Taba di dalam Kurinasih dan Sani (2014) Curriculum is a plan for learning. (kurikulum adalah rencana pembelajaran).

Menurut Sukmadinata di dalam Wahyuddin (2014) pengembangan kurikulum bisa berarti penyusunan kurikulum yang sama sekali baru, bisa juga menyempurnakan kurikulum yang telah ada. Selanjutnya beliau menjelaskan, pada satu sisi pengengbangan kurikulum berarti seluruh perangkat kurikulum mulai dari menyusun dasar-dasar kurikulum, struktur dan sebaran mata pelajaran, garis- garis besar program pengajaran, sampai dengan pedoman- pedoman pelaksana. Pada sisi lainnya berkenaan dengan penjabaran kurikulum yang telah disusun oleh tim pusat menjadi rencana dan persiapanpersiapan mengajar yang lebih khusus yang di kerjakan oleh guru-guru di sekolah, seperti penyusunan program tahunan, program semester, minggu efektif, analisis kompetensi inti $(\mathrm{KI}) /$ kompetensi dasar (KD), rencana pelaksanaan pembelajaran (RPP) dan lainnya.

\section{METODE PENELITIAN}

Penelitian ini menggunakan metode deskriptif, pendekatan kualitatif. Sugiyono (2013) data kualitatif adalah data yang berbentuk kata, kalimat, gerak tubuh, ekspresi wajah, bagan, dan gambar foto. Demikian juga Patilima (2011) menyatakan alasan penggunaan pendekatan kualitatif adalah penelitian tersebut bertujuan memahami suatu situasi sosial, peristiwa, peran, interaksi, dan kelompok. Dengan demikian, dalam penelitian ini tidak bermaksud untuk mencari teori-teori baru. Menurut Creswell di dalam Patilima (2011) bahwa pendekatan kualitatif merupakan sebuah proses investigasi. Secara bertahap peneliti berusaha memahami fenomena sosial dengan membedakan, membandin kan, meniru, mengkatalogkan, dan mengelompokkan objek studi. Peneliti memasuki dunia informan dan melakukan interaksi terus-menerus dengan informan, dan mencari sudut 
pandang informan. Subjek penelitian ini adalah pengawas, kepala sekolah, wakil kepala sekolah bidang kurikulum, guru bidang studi, dan guru pendamping. Variabel penelitian ini terdiri dari satu variabel bebas yaitu kinerja guru dan satu variabel terikat yaitu Kurikulum 2013.

Teknik pengumpulan data yaitu melalui observasi, wawancara, dan studi dokumentasi. Sugiyono (2013) menyatakan pengumpulan data dapat dilakukan dalam berbagai setting, berbagai sumber, dan berbagai cara. Bila dilihat dari setting-nya, data dapat dikumpulkan pada setting alamiah (natural setting), pada laboratorium dengan metode eksperimen, di sekolah dengan tenaga pendidikan dan kependidikan, di rumah dengan berbagai responden, pada suatu seminar, diskusi, di jalan dan lain-lain. Data dan informasi yang telah diperoleh peneliti selanjutnya, dianalis dan diinterpretasikan mulai awal penelitian sampai akhir penelitian dengan merujuk landasan teori yang berhubungan dengan masalah yang diteliti. Analisis data dalam penelitian kualitatif ini dilakukan dengan cara menggolongkan, mengarahkan, membuang yang tidak perlu, danmengorganisasi data (mereduksi data), merangkum hal-hal pokok (display data) dan penarikan kesimpulan (verifikasi data).

\section{HASIL DAN PEMBAHASAN}

\section{Kemampuan Guru dalam Implementasi Kurikulum 2013 di SMA Islam Al-Ma'arif}

\section{Pandan Indah Kabupaten Lombok Tengah Provinsi Nusa Tenggara Barat.}

Hasil penelitian penulis membuktikan bahwa kemampuan guru di SMA Islam AlMa'arif Pandan Indah Kabupaten Lombok Tengah Provinsi Nusa Tenggara Barat sudah ba ik namun belum optimal dalam merencanakan pembelajaran, melaksanakan proses pembel ajaran, dan mengevaluasi hasil pembelajaran. Untuk mengetahui lebih jauh tentang kinerja guru di SMA islam al-ma'arif pandan indah kabupaten Lombok tengah provinsi nusa tenggara barat, dapat ditinjau dari beberapa aspek: (1) kemampuan guru dalam merencanakan, melaksanakan, dan mengevaluasi proses dan hasil pembelajaran (2) motivasi guru (3) komitmen dan tanggung jawab guru, dan (4) faktor pendukung dan penghambat dalam implementasi K-13. emampuan guru dalam perencanaan pembelajaran.

Hasil penelitian membuktikan bahwa dalam implementasi Kurikulum 2013 di SMA islam al-ma'arif pandan indah kabupaten Lombok tengah provinsi nusa tenggara barat sebagi-an besar guru sudah mampu merumuskan kegiatan perencanaan pembelajaran dan sebagian kecil belum. Seperti merumuskan tujuan mata pelajaran yang akan diajarkan, menentukan kom-petens inti, kompetensi dasar, indikator, materi ajar dalam pokok 
bahasan dan sub pokok ba-hasan, strategi belajar mengajar, media pembelajaran, kegiatan pembelajaran, tehnik evaluasi, alokasi waktu, dan sumber belajar. Hal tersebut dijelaskan langsung oleh kepala sekolah yang menyatakan bahwa sekitar 50\% guru sudah mempersiapkan RPP mereka sesuai dengan for-mat yang dianjurkan dalam Permen No 103 tahun 2014 yaitu dimana rencana pelaksanaan pembelajaran (RPP) sudah dikembangkan dari silabus oleh setiap guru sesuai dengan standar isi (SI) dan penyusunan RPP sudah menggunakan prinsip perbedaan individu peserta didik dan menerapkan teknologi informatika (TI) dan komunikasi. Sekitar 50\% lagi guru RPPnya tidak sesuai dengan format karena tidak melampirkan instrumen penilaian, pedoman penilaian, kisi-kisi soal, kartu soal, program remedial, dan pengayaan. Kemampu-an guru dalam pelaksanaan pembelajaran.

Hasil penelitian membuktikan bahwa Kemampuan guru dalam pelaksanaan pembelajaran di SMA islam al-ma'arif pandan indah kabupaten lombok tengah provinsi nusa tenggara barat dilihat dari tugas pokok guru dalam pelaksanaan pembelajaran sudah terimplementasikan dari RPP yang disusun meliputi kegiatan pendahuluan, inti, dan penutup sudah menunjukkan kinerja yang baik. Selanjutnya, implementasi K-13 yang dilakukan oleh guru guru di SMA Islam Al Ma'arif Pandan Indah Kabupaten Lombok Tengah Provinsi Nusa Tenggara Barat sudah relevan dengan perencanaan pengajaran yang su-dah dipersiapkan oleh masing-masing guru, hanya sa-ja dalam penyampaian materi ajar, guru menyesuaikannya dengan kemampuan siswa, serta alokasi waktu yang telah ditentukan. Hasil wawancara penulis dengan seorang pengawas bahwa saat mengajar, sebagian guru sudah mengetahui kandungan materi yang akan disam-paikan di kelas, metode pengajaran yang akan digunakan, termasuk media dan alat peraga yang digunakan logis dan dapat dipahami dengan mudah oleh siswa. Namun demikian dalam proses pembelajaran para guru masih mengalami kesulitan dalam mengelola waktu dan meningkatkan minat belajar para siswa. Agar pelaksanaan perencanaan kurikulum dapat ber-jalan dengan baik, guru harus aktif mengembangkan potensi dirinya baik melalui diskusi dengan teman sejawat, melalui pelatihan atau penataran, maupun keaktifan dalam forum Musyawarah Guru Mata Pelajaran (MGMP). Hal ini sesuai dengan pernyataan Jackson \& Bruegmann di dalam Stosich (2016) state that Collaboration among teachers can provide op-portunities for techers to learn from more effective collegues, encourage teachers to experiment with new instructional approaches, enhance teahers' confidene in their ability to improve stu-dents learnin outcomes. Maksud dari pernyataan diatas adalah dengan aktif mengikuti kegiatan MGMP, maka guru akan memiliki sifat yang dinamis 
terhadap perkembangan pen-didikan dan akan timbul kepercayaan dirinya. Karena Guru akan menyadari kekurangannya dan akan penggalian potensi dirinya, sehingga hasil yang selama ini diperoleh kurang, bisa menjadi maksimal sehingga akan meningkatkan bela-jar siswa. Kemampuan guru dalam mengevaluasi pembelajaran.

Hasil penelitian membuktikan bahwa kemampuan guru dalam mengevaluasi pembelaja-ran di SMA Islam Al-Ma'arif Pandan Indah Kabupaten Lombok Tengah Provinsi Nusa Tenggara Barat dilihat dari tugas utama guru dalam pengevaluasian menunjukkan kinerja yang kurang baik. Hal tersebut dijelaskan langsung oleh kepala sekolah yang mengatakan bahwa nilai kriteria ketuntasan minimum (KKM) setiap mata pelajaran sudah ditentukan pada awal tahun ajaran melalui rapat dewan pendidik dan MGMP mata pelajaan. Tapi kenyataannya di lapangan ada beberapa guru hanya melakukan penilaian pada aspek pengetahuan dan ket-erampilan saja, se-dangkan untuk penilaian sikap luput dari penilaian mereka. Sebagian guru mengatakan bahwa tidak melakukan penilaian sikap karena tidak ada waktu, susah membuat instrumennya, dan sebagainya.

Sejalan dengan penjelasan diatas maka Hargreaves and Lorna Earl di dalam Amat J.E et al (2014) menyatakan bahwa The authentic assessment is an assessment could motivate stu-dents to be more responsible for their own learning, make the assessment as an intergral part of the learning process encourage learners to be more creative, and apply knowledge rather than merely train memory yang artinya penilaian autentik dapat memotivasi siswa untuk ber-tanggung jawab terhadap belajarnya, penilaian juga bagian yang dapat mendorong proses belajar siswa lebih kreatif dalam mempergunakan ilmu yang telah dikuasainya dari pada hanya sekedar melatih ingatan.

Mengingat pentingnya penilaian dalam menentukan kualitas pendidikan, maka upaya yang harus dilakukan oleh pihak sekolah dalam membantu para guru dalam memahami cara dan teknik penilaian dalam K-13 dengan memberi pelatihan tentang sistem penilaian, khu-susnya penilaian sikap. Dengan demikian guru tahu cara menilai dengan benar.

\section{Motivasi Guru Dalam Implimetasi Kurikulum 2013 Di Sma Islam Al Ma'arif Pandan Indah Kabupaeten Lombok Tengah Nusa Tenggara Barat}

Hasil penelitian membuktikan bahwa kinerja guru di SMA islam al-ma'arif pandan indah kabupaten lombok tenah provinsi nusa tenggara barat ditinjau dari motivasi kerja guru menunjukkan gairah kerja yang baik dan semua bidang pekerjaan dilakukan secara bersa-ma-sama. Deskripsi tersebut sesuai dengan pernyataan kepala sekolah SMA islam al- 
ma'arif pandan indah kabupaten lombok tengah provinsi nusa tenggara barat bahwa selama ini mo-tivasi kerja para guru sudah menunjukkan kinerja baik, hanya saja membutuhkan keseriusan dan keikhlasan dalam bekerja. Karena banyak pekerjaan yang harus segera diselesaikan, tetapi tidak dibayar, disinilah dituntut keikhlasan para guru dalam pengabdian mereka kepada pendidikan. Oleh karena itu semua hal yang dilakukan selama ini harus diniatkan sebagai ibadah yang dipersembahkan kepada bangsa dan negara.

Usman (2012) menyebutkan bahwa motivasi kerja merupakan salah satu indikator keberhasilan seseorang dalam melaksanakan sesuatu kegiatan atau pekerjaan. Dengan motivasi yang dimiliki seseorang dapat membentuk sikap dan nilai terhadap pekerjaan. Motivasi memiliki peranan penting dalam menciptakan kinerja yang tinggi di kalangan guru atau anggota organisasi. Dengan motivasi diharapkan anggota organisasi dapat melakukan berbagai kegiatan organisasi dalam rangka mencapai kebutuhan anggota dan tujuan organisasi. Motivasi merupakan keinginan yang kuat dengan upaya yang memadai untuk memperoleh sesuatu yang diinginkan.

\section{Komitmen dan Tanggung Jawab Guru dalam Implementasi Kurikulum 2013 di SMA Islam Al-Ma'arif Pandan Indah Kabupaten Lombok Tengah Provinsi Nusa Tenggara Barat.}

Hasil penelitian membuktikan bahwa kinerja guru di SMA islam al-ma'arif pandan indah kabupaten Lombok tengah provinsi nusa tenggara barat ditinjau dari komitmen dan tanggung jawab guru menunjukkan hasil kerja yang baik dan semua bidang pekerjaan dilakukan dengan kesungguhan hati dan sebaik- baiknya. Deskripsi tersebut senada dengan pernyataan kepala SMA al-ma'arif pandan indah kabupaten Lombok tengah provinsi nusa tenggara barat bahwa guru-guru di SMA al-ma'arif pandan indah kabupaten Lombok tengah provinsi nusa tenggara barat sebagian besar memiliki kepribadian, dedikasi, dan loyalitas yang tinggi dalam bekerja. Hal ini tercermin dalam aktifitasnya sehari- hari dalam mengelola pembelajaran, membimbing siswa, dan kemampuan guru dalam mengklarifikasi masalah-masalah pembelajaran, dan menentukan alternatif pemecahannya khususnya dalam pelaksanaan Kurikulum 2013.

Usman (2012) menyatakanbahwakomitmen terhadap tugas guru dapat menunjukkan perilaku yang sungguh-sungguh terhadap pencapaian target dan hasil-hasil setiap pembelajaran sesuai apa yang telah ditetapkan dalam tugas pokok dan fungsinya. Guru yang memiliki kinerja yang baik tentunya memiliki komitmen yang tinggi dalam pribadinya artinya tercermin suatu kepribadian dan dedikasi yang paripurna. 
Faktor Pendukung dan Penghambat dalam Implementasi Kurikulum 2013 di SMA islam al-ma'arif pandan indah kabupaten Lombok tengah provinsi nusa tenggara barat Koordinasi dalam implementasi Kurikulum 2013.

Hasil penelitian di SMA islam al-ma'arif pandan indah kabupaten Lombok tengah provinsi nusa tenggara barat membuktikan bahwa tidak ada hambatan yang berarti yang dihadapi oleh para guru dalam menerapkan K-13. Hal ini dikarenakan adanya koordinasi yang baik antara kepala sekolah dengan para guru dan tenaga kependidikan lain termasuk komite sekolah melalui pertemuan informal maupun formal. Sehingga dapat dipahami bahwa koordinasi sangat penting dalam menjalankan suatu kegiatan atau program, khususnya dalam implementasi Kurikulum 2013.

\section{Komunikasi dalam Implementasi Kurikulum 2013 di SMA Islam Al-Ma'arif Pandan Indah Kabupaten Lombok Tengah Provinsi Nusa Tenggara Barat.}

Hasil penelitian membuktikan bahwa komunikasi yang dilakukan oleh kepala sekolah dengan guru dan personil lainnya di sekolah sudah baik, terutama dengan komite sekolah dan orang tua siswa dalam pelaksanaan K-13. Walaupun demikian masih ada sebagian dari guru yang susah untuk menerima kurikulum baru tersebut, hal ini dikarenakan mereka sudah nyaman dengan kurikulum lama, terutama dalam pendekatan pembelajaran dan sistem penilaian.

Supervisi dalam implementasi Kurikulum 2013 Supervisi yang dilakukan oleh kepala sekolah dan dibantu oleh guru pendamping kepada guru dan personil lainnya di sekolah sudah baik, dalam pelaksanaan Kurikulum 2013. Walaupun demikian masih ada sebagian dari guru tidak mau kalau disupervisi oleh kepala sekolah dan guru pendamping dengan berbagai macam alasan. Hal ini dikarenakan mereka tidak mau kalau kelemahan atau kekurang mengajarnya diketahui oleh orang lain.

Menurut Wiles di dalam Purwanto (2009) supervisi merupakan bantuan dalam pengembangan situasi belajar mengajar. Demikian juga menurut Dickey di dalam Mukhtar dan Iskandar (2010) supervisi adalah program yang berencana untuk memperbaiki pengajaran.

\section{SIMPULAN}

Kemampuan guru guru SMA Islam Al-Ma'arif Pandan Indah Kabupaten Lombok Tengah Provinsi Nusa Tenggara Barat dalam implementasi Kurikulum 2013 sudah baik namun belum optimal terutama dalam perencanaan pembelajaran dalam penyusunan RPP 
tidak sistematis. Pelaksanaan pembelajaran kurang menerapkan partisipasi aktif peserta didik dan pengelolaan waktu yang tidak efektif. Pengevaluasian proses pembelajaran tidak autentik dan komprehensif terutama dalam penilaian sikap.

Motivasi guru-guru SMA islam al-ma'arif pandan indah kabupaten Lombok tengah provinsi nusa tenggara barat dalam melaksanakan tugas sudah baik, tercermin dari sikap yang ditampilkan oleh para guru terhadap pekerjaannya dan situasi yang kondusif yang mereka rasakan di sekolah serta terciptanya iklim kekeluargaan di kalangan para guru dan personil sekolah. Dengan motivasi yang tinggi para guru dan anggota organisasi sekolah sudah dapat melakukan berbagai kegiatan dalam rangka mencapai tujuan sekolah.

Guru SMA Islam Al-Ma'arif Pandan Indah Kabupaten Lombok tengah provinsi nusa tenggara barat sudah memiliki komitmen dan tanggung jawab yang baik dalam bekerja, hal ini tentunya nampak dalam kinerja yang ditampilkan oleh mereka, artinya tercermin dalam kepribadian, dedikasi dan loyalitas mereka dalam bekerja. Mereka bekerja dengan sungguh-sungguh dan ikhlas untuk terlaksananya Kurikulum 2013.

Dukungan dan hambatan yang dihadapi guru SMA islam al-ma'arif pandan indah kabupaten Lombok tengah provinsi nusa tenggara barat dalam implementasi K-13 dari aspek: koordinasi dalam implementasi Kurikulum 2013 sudah dilakukan oleh pihak sekolah dengan instansi terkait demi kelancaran pelaksanaan K-13, komunikasi yang dilakukan oleh kepala sekolah dengan guru dan personil lainnya berjalan lancar, dan supervisi kepala sekolah yang dibantu oleh guru pendamping belum terlaksana secara optimal karena ketidaksiapan guru dan juga kesibukan kepala sekolah.

\section{SARAN}

1. Proses kinerja guru dalam implementasi kurikulum 2013 berjalan dengan baik jika sekolah dapat memahami konsep pelaksanaannya dengan baik. Oleh karena itu, diperlukan pelatihan dan pendampingan tentang kurikulum K-2013 baik dari sekolah maupun pemerintah.

2. Peroses penilaian di sekolah yang berdasarkan kurikulum K-2013 dapat dikatakan sudah berjalan dengan cukup baik. Dalam hal ini hendaknya menjadi motivasi bagi sekolah untuk terus meningkatkan kualitas pendidikan agar tujuan pendidikan dapat tercapai.

3. Guru sebagai pelaksanaan kegiatan pembelajaran diharapkan dapat memahami implimentasi K-2013 dengan dengan baik terutama dalam peroses pembelajaran. Oleh 
karena itu, dapat di lakukan dengan memaksimalkan peran MGMP dan banyak mengikuti pelatihan tentang K-2013 baik di adakan oleh sekolah maupun pemerintah.

4. Dengan adanya kendala-kendala yang di alami sekolah dalam implimentasi K-2013 di harapkan dapat dijadikan motivasi agar dapat memperbaiki diri dan mampu menerapkan K-2013 dengan semaksimal mungkin.

\section{DAFTAR PUSTAKA}

Amat J. E et al. (2014). An evaluation of the implementation of Curriculum 2013 at the building construction department of vocational high schools in Yogyakarta.

Kurinasih, Iman dan Sani, Berlin. (2014). Implementasi Kurikulum 2013: Konsepdan Pene rapan, Surabaya: Kata Pena.

Mukhtar dan Iskandar. (2010). Supervisi Pendidikan, Bandung: Remaja Rosdakarya.

Mulyasa, H, E. (2014). Guru Dalam Implementasi Kurikulum 2013, Bandung:Remaja Ros dakarya.

Patilima, Hamid. (2011). Metode Penelitian kualitatif, bandung: Balai Pustaka.

Poerwadarminta. (2010). Kamus Bahasa Indonesia, Jakarta: Balai Pustaka.

Purwanto, M Ngalim. (2009). Administrasi dan Supervisi Pendidikan,Bandung: Remaja Rosdakarya.

Usman, Nasir. (2012). Manajemen peningkatan mutu kinerja guru. Bandung: Cipta pustaka Media Perintis.

UU, No. 20 Tahun 2003. Tentang sistem pendidikan nasional. Bandung: Citra Umbara.

Whayudin, Dinn. (2004). Manajemen kurikulum. Bandung: Remaja Rosdakarya.

Wibowo. (2004). Manajemen Kinerja. Jakarta: Raja Grafindo Persada 